\title{
Crack Patterns in Reinforced and Fiber Reinforced Concrete Structures
}

\author{
B. Chiaia*, A. P. Fantilli and P. Vallini
}

Department of Structural and Geotechnical Engineering, Politecnico di Torino, Italy

\begin{abstract}
The cracking phenomenon of members made of traditional reinforced concrete (RC) or by combining steel fibers and traditional reinforcing bars (R/FRC) is analyzed in this paper. Referring to the tensile zone of a beam subjected to bending moment and axial load, a unique block model is introduced to predict crack widths, crack lengths and crack distances. The proposed approach, based on the nonlinear behaviour of the cracked cement-based material in tension, and on the bond-slip interaction between rebars and concrete, provides crack patterns similar to those observed in different experimental campaigns. Cracks in R/FRC beams are generally narrower, and originate at small distances, than those observed in RC beams having the same geometry and reinforcement ratio. This is entirely due to the presence of fibers, here considered through the Reinforcing Index, which is the product of volume percentage and fiber aspect ratio. However, the beneficial effect of fiber-reinforcement vanishes with the increase of structural dimension. Thus, in the case of massive structures, it appears necessary a direct calculation of the crack width, even in the presence of fibers.
\end{abstract}

\section{INTRODUCTION}

To obtain more durable and economic concrete structures, the combination of steel fibers and reinforcing bars represents a competitive design solution. In fiber reinforced concrete (FRC), the traditional rebars keep the main bearing function, but the global amount of steel can be significantly lower than that of classical reinforced concrete (RC). This is particularly true for lightly reinforced concrete structures subjected to bending and axial loads, like the massive structures of tunnel linings, where the combination of fibers and rebars (R/FRC structures) gives an increase of ductility [1].

In the case of beams in bending, due to the presence of fibers, tensile cracks are usually narrower and originate at small distances [2]. As a consequence, the vulnerability of steel bars to corrosion is reduced and, contemporarily, the durability of concrete structures is increased. Therefore, the prediction of crack pattern, in terms of crack width $w$ and crack distance $s_{\mathrm{r}}$, is a fundamental point for the definition of the correct amount of steel reinforcement. Unfortunately, the evaluation of $w$ and $s_{\mathrm{r}}$ in $\mathrm{RC}$ and $\mathrm{R} / \mathrm{FRC}$ beams under bending and compression still remains an open problem. Despite the huge amount of investigations on RC structures in more than a century (see (Borosnyoi and Balazs) [3] for a review), the existing formulae for evaluating crack width and crack spacing are not unanimously accepted. As a matter of fact, while the American Concrete Institute [4] suggests an empirical approach for the evaluation of $w$ (derived from the tests by (Gergely and Lutz) [5], which is independent of crack distance, both CEB-FIP Model Code 90 [6] and (Eurocode 2) [7] recommend the following semi-empirical formula:

$w_{k}=s_{r, \max }\left(\varepsilon_{s m}-\varepsilon_{c m}\right)$

*Address correspondence to this author at the Department of Structural and Geotechnical Engineering, Politecnico di Torino, Italy;

E-mail: bernardino.chiaia@polito.it where, $w_{\mathrm{k}}=$ characteristic value of crack width; $\varepsilon_{\mathrm{sm}}=$ mean strain in the reinforcement between the cracks; $\varepsilon_{\mathrm{cm}}=$ mean strain in the concrete between the cracks; and $S_{\mathrm{r}, \max }=$ maximum crack spacing computed with:

$s_{r, \text { max }}=k_{3} c+k_{1} k_{2} k_{4} \frac{\Phi}{\rho}$

where, $k_{1}, k_{2}, k_{3}, k_{4}=$ non dimensional coefficients [7]; $\phi=$ bar diameter; and $\rho=$ effective reinforcement ratio (the ratio between the area of reinforcement $A_{\mathrm{s}}$ contained within the effective concrete area in tension $\left.A_{\mathrm{c}, \text { eff }}\right)$. This approach has been extended to R/FRC structures by the $\sigma-\varepsilon$ design method suggested by Rilem TC 162-TDF (8). More precisely, according to some experimental results [9], the crack width of FRC beams with rebars can be always predicted with Eq.(1), independently of the amount of steel fibers added to the concrete matrix. On the contrary, the fiber aspect ratio $L / D$ ( $L=$ fiber length; $D=$ fiber diameter) is taken into account in the formula for the evaluation of the maximum distance between cracks, which appears different from Eq. (2) (see [8]):

$s_{r, \max }=\beta s_{r, m}=\beta\left(k_{3}+k_{1} k_{2} k_{4} \frac{\Phi}{\rho}\right) \frac{k_{5}}{L / D}$

where, $\beta=$ coefficient relating the average crack spacing to the design value; $s_{\mathrm{r}, \mathrm{m}}=$ average final crack spacing; and $k_{1}$, $k_{2}, k_{3}, k_{4}, k_{5}=$ non dimensional coefficients [8]. Eqs.(1-3) are not always effective for the prediction of real crack patters in $\mathrm{RC}$ and $\mathrm{R} / \mathrm{FRC}$ members subjected to bending moment and normal forces. It is sufficient to recall that crack width is arbitrarily assumed to be in direct proportion with a unique value of crack distance, generally measured at stabilized crack pattern by Eqs. (2-3).

In a more realistic approach, $w$ and $s_{\mathrm{r}}$ have to be computed contemporaneously by means of a block model like the one already introduced by (Fantilli and Vallini) [10] for $\mathrm{RC}$ and $\mathrm{R} / \mathrm{FRC}$ elements in tension. In this way, all the physical phenomena which affect the evolution of crack 


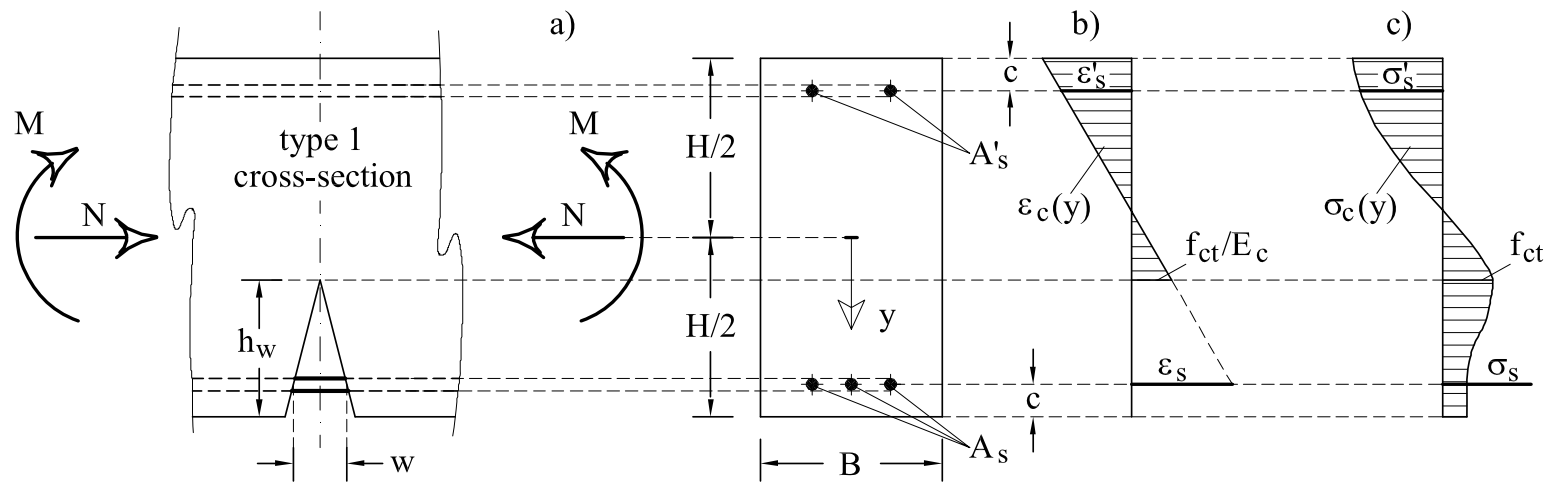

Fig. (1). The cracked cross-section (type 1) subject to $M-N$ : a) geometrical properties; b) strain profile; c) stress profile.

pattern (i.e. the bond-slip mechanism between steel and concrete and the nonlinear fracture mechanics of the cementbased material in tension) can be taken into account. Thus, the main target of this paper is to introduce an effective procedure for the prediction of crack pattern in $\mathrm{RC}$ and $\mathrm{R} / \mathrm{FRC}$ members under combined bending and compression. In particular, for lightly reinforced concrete structures, this model has to be used together with that already introduced by (Chiaia et al.) [1] for the evaluation of the minimum amount of steel rebars. In fact, according to (Levi) [11], the criteria used to establish the minimum reinforcement percentages may regard both the ultimate limit state of the structure (i.e. the reinforcement must be dimensioned so that at the onset of cracking, the tensile stresses acting on the rebars will be prevented from exceeding the elastic limit of steel) and the serviceability conditions (i.e. the local interaction between steel and concrete must keep the crack width within pre-established limits).

\section{THE EVALUATION OF CRACK PATTERN}

In $\mathrm{RC}$ and $\mathrm{R} / \mathrm{FRC}$ beams, subjected to either constant or variable bending moments, it is practically impossible to predict a unique evolution of crack pattern [12]. For these structures, due to the random nature of cracking, it appears more appropriate to define, for a given pair of applied actions $M-N$ (where, $M=$ bending moment; and $N=$ normal force), the maximum and the minimum values of crack width and crack spacing. This is possible by introducing a suitable block of FRC beam, in which $w$ and $s_{\mathrm{r}}$ are computed by considering not only the bond-slip mechanisms between rebars and concrete in tension, but also the nonlinear behaviour of cracked concrete under tensile actions. In this way, the states of stress and strain in the cracked crosssection (called type 1) of the block can be defined. As shown in Fig. (1), for given crack width $w$ (measured at the level of reinforcement) and crack depth $h_{\mathrm{w}}$ (Fig. 1a), under the hypothesis of a linear strain profile between uncracked concrete and rebars in tension (Fig. 1b), strains in concrete . $\sigma_{\mathrm{c}}(y)$ and steel in tension $\varepsilon_{\mathrm{s}}$ and compression $\varepsilon_{\mathrm{s}}^{\prime}$. [and the related stresses $\sigma_{\mathrm{c}}(y), \sigma_{\mathrm{s}}$ and $\sigma_{\mathrm{s}}^{\prime}$ ] can be obtained through the following equilibrium equations (Fig. 1c):

$$
\begin{aligned}
& N=\int_{A_{c}} \sigma_{c}(y) d A+\sigma_{s} A_{s}+\sigma_{s}^{\prime} A_{s}^{\prime} \\
& M=\int_{A_{c}} \sigma_{c}(y) y d A+\sigma_{s} A_{s}\left(\frac{H}{2}-c\right)+\sigma_{s}^{\prime} A_{s}^{\prime}\left(\frac{H}{2}-c\right)
\end{aligned}
$$

where, $y=$ vertical coordinate; $c=$ concrete cover; $A_{\mathrm{c}}=$ area of concrete; $A_{\mathrm{s}}, A^{\prime}{ }_{\mathrm{s}}=$ cross-sectional areas of steel rebars in tension and compression, respectively; $H=$ height of the beam cross-section.

In a beam under bending and compression, the maximum crack width, corresponding to the applied loads $M-N$, is reached at incipient formation of new cracks [10], when also the crack distance is maximum. In general, due to the formation of a secondary crack pattern, the distances between primary cracks are halved and their widths are reduced [13].

The condition of incipient formation of a secondary crack is schematized in Fig. (2a), where in a cross-section (called type 2) the tensile strength of concrete $f_{\text {ct }}$ is reached at the lower edge in tension, while at the level of reinforcement, concrete reaches the critical strain $\varepsilon_{\mathrm{c}, \text { crit }}$. For the sake of simplicity, the strain profile is assumed to be bilinear: one slope for concrete in compression and steel bars in tension,

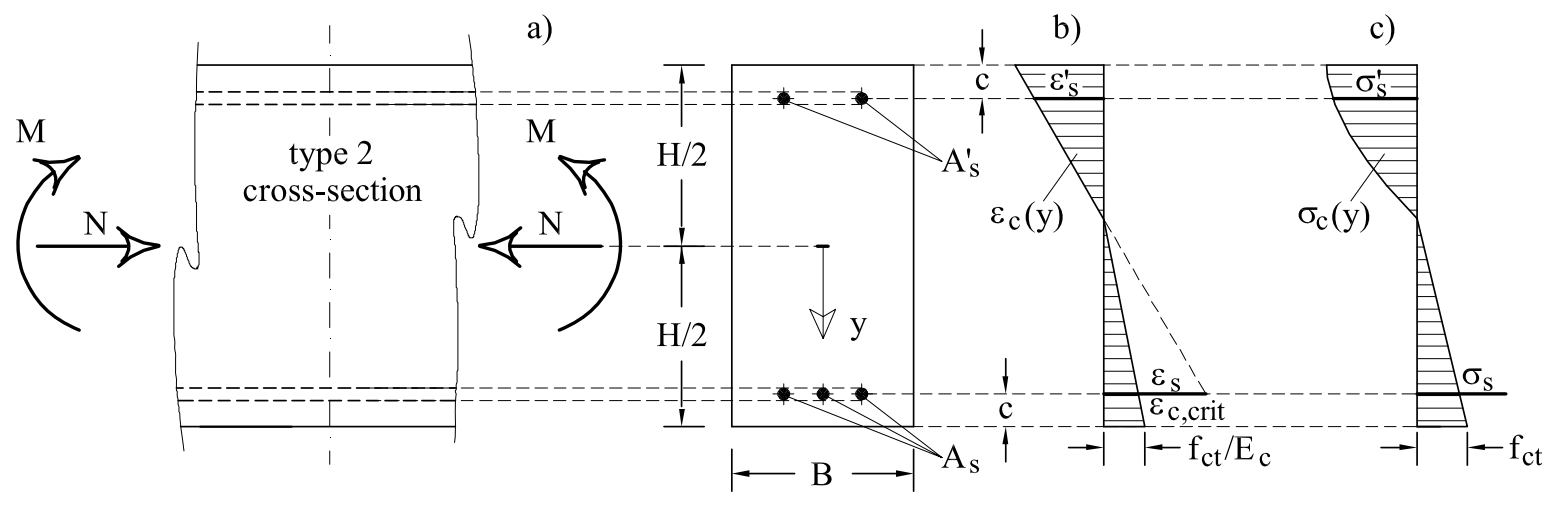

Fig. (2). The cross-section at incipient cracking (type 2) subject to $M-N$ : a) geometrical properties; b) strain profile; c) stress profile. 
whereas the other slope depicts concrete in tension (Fig. 2b). Also for type 2 cross-section, when $M-N$ are known, strains in concrete $\varepsilon_{\mathrm{c}}(y)$ and steel (in tension $\varepsilon_{\mathrm{s}}$ and in compression $\left.\varepsilon_{\mathrm{s}}^{\prime}\right)$, as well as the related state of stress $\sigma_{\mathrm{c}}(y), \sigma_{\mathrm{s}}$ and $\sigma_{\mathrm{s}}^{\prime}$, can be obtained from Eqs.(4a-b) (Fig. 2c).

The type 1 cross-section in Fig. (1) (cracked crosssection) and type 2 cross-section in Fig. (2) (cross-section at incipient cracking) limit the considered block (Fig. 3a), which reproduces the half beam's portion between two consecutive primary cracks at incipient formation of a secondary crack in between. Stresses and strains in the steel bars in tension, and in the surrounding concrete of the block, can be calculated by the classical tension-stiffening equations:

$\frac{d \sigma_{s}}{d z}=-\frac{p_{s}}{A_{s}} \cdot \tau$

$\frac{d s}{d z}=-\varepsilon_{s}(z)+\varepsilon_{c}(z)$

where, $p_{\mathrm{s}}$ and $A_{\mathrm{s}}=$ respectively, the perimeter and the crosssectional area of reinforcing bars in tension; $s=$ value of slip between reinforcing bars and concrete; $\varepsilon_{\mathrm{s}}$ and $\varepsilon_{\mathrm{c}}=$ strains, respectively computed in the steel area in tension and in the tensile concrete at the same level of reinforcement $(y=H / 2$ c); $z=$ horizontal coordinate; and $\tau=$ bond stress between steel and concrete.

If the constitutive relationship $\sigma-\varepsilon$ of the materials, the cohesive law $\sigma-w$, and the bond slip relationship $\tau$-s are known, the complete analysis of the block can be performed. To be more precise, for given values of $N$ and crack width $w$ referred to the level of reinforcement, the relationship between crack width $w$ and bending moment $M$ can be obtained by solving Eqs.(4-6) with the following boundary conditions (Fig. 3a): $s(z=0)=w / 2$ (in the type 1 crosssection, where $z=0)$ and $\varepsilon_{\mathrm{c}}\left(z=l_{\mathrm{tr}}\right)=\varepsilon_{\mathrm{c}, \mathrm{crit}}$ (at the level of reinforcement in type 2 cross-section, where $z=l_{\text {tr }}$ ). Due to the symmetry, in the type 2 cross-section $s=0$ should be also verified.

\section{Constitutive Relationships}

In the proposed model, suitable $\sigma-w$ and $\varepsilon-s$ relationships have to be taken into account. For instance, those proposed by CEB-FIP Model Code 90 [6] can be adopted for the cohesive behaviour of concrete (Fig. 4a) and for the interaction between steel bars and ordinary concrete (Fig. 4b). As is well known, the definition of such relationships is based on the values of compressive strength $f_{\mathrm{c}}$ and of the maximum diameter $d_{\mathrm{a}}$ of the aggregate.

In the case of FRC, the structural effects produced by the fibers are computed by means of new models. In particular, the bond slip model proposed by (Harajli et al.) [14] is here adopted for the interaction between steel bars and FRC. Compared to the model adopted for $\mathrm{RC}$ structures, the relationship is more or less the same, except for its parameters. This is particularly true in the first ascending branch, which is of crucial importance in the serviceability stage of R/FRC members (Fig. 4b):

$$
\tau=\tau_{\max }\left(\frac{s}{s_{1}}\right)^{\alpha}
$$

where, $\tau_{\max }=$ maximum value of bond stress; $s_{1}=$ slip at $\tau_{\max }$; and $\alpha=$ exponent of slip ratio.

Regarding the behaviour of FRC in tension and compression, it is possible to follow the $\sigma-\varepsilon$ approach proposed by Rilem TC 162- TDF [8] by adopting the stressstrain relationship depicted in Fig. (4c). The compressive behaviour is the classical parabola-rectangle diagram proposed by (Eurocode 2) [7] for ordinary concrete. Instead, the part in tension is assumed to be linear up to the tensile strength $f_{\mathrm{ct}}$ of the cement-based material. In the case of fiber reinforced composites, after the peak, a bi-linear relationship is taken into consideration. The parameters of such relationship are defined by measuring the residual strength $f_{\mathrm{R}, 1}$ and $f_{\mathrm{R}, 4}$ of notched FRC beams under three point bending [8]. According to (Chiaia et al.) [1], the relationship of the fictitious crack model can be indirectly obtained from the $\sigma-$ $\varepsilon$ diagram of Fig. (4c). It is sufficient to localize the postpeak branch in tension within a softening region, having a length equal to that of the adopted fibers (characteristic length).

In this paper only the serviceability stages of $\mathrm{RC}$ and $\mathrm{R} / \mathrm{FRC}$ beams are investigated, thus the steel reinforcing bars are assumed to stay always in the linear elastic regime.

\section{Solution of the Problem}

The model analytically described in the previous paragraphs can be numerically solved by the following iterative procedure (Fig. 3):

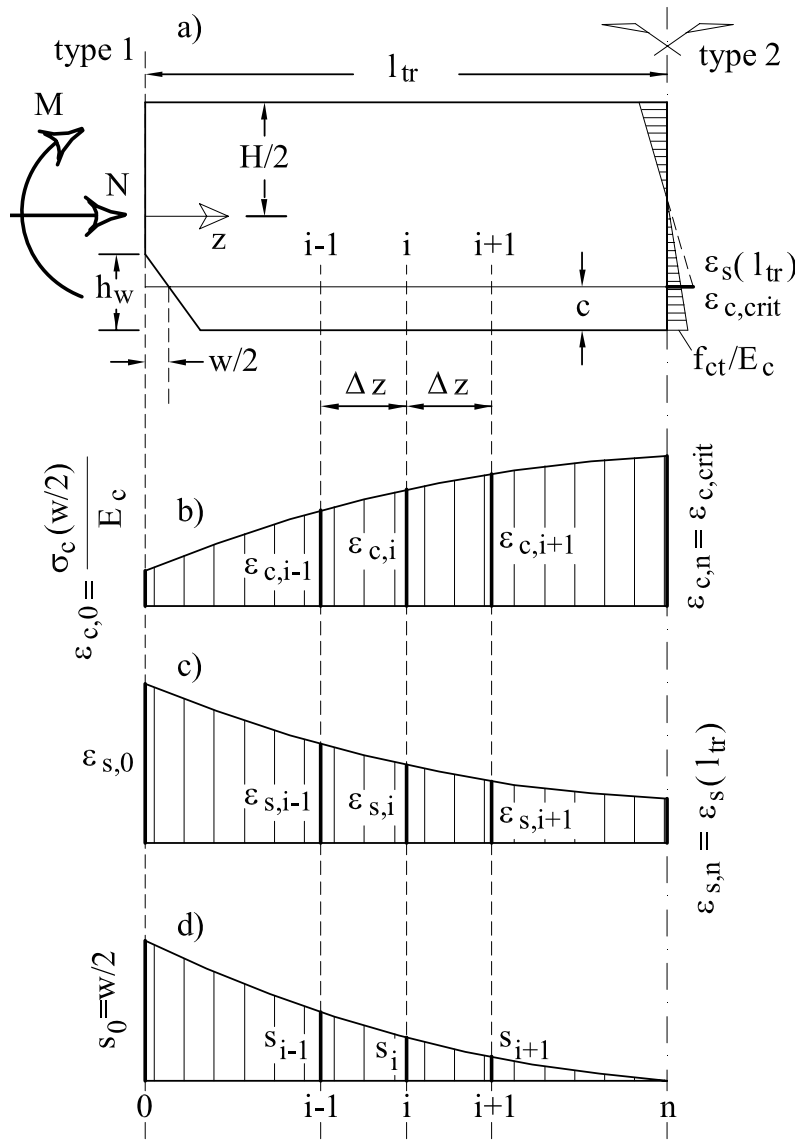

Fig. (3). The block of the beam used for the evaluation of crack pattern: a) position of type 1 and type 2 crosssections; b) concrete strains at level of steel reinforcing bars in ten-sion; c) strains in the reinforcement in tension d) slip between steel and concrete. 

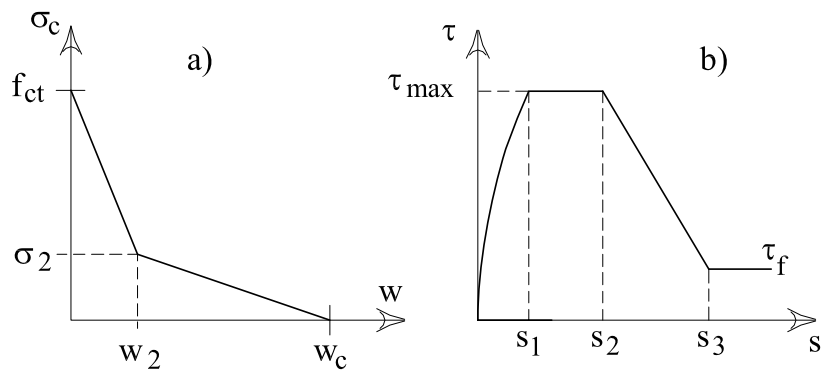

\begin{tabular}{|c|c|c|}
\cline { 2 - 3 } \multicolumn{1}{c|}{} & RC [6] & R/FRC [14] \\
\hline$\tau_{\max }$ & $2 \sqrt{\mathrm{fc}_{\mathrm{c}}}$ & $2.57 \sqrt{\mathrm{fc}_{\mathrm{c}}}$ \\
\hline$\tau_{\mathrm{f}}$ & $0.15 \tau_{\max }$ & $0.15 \tau_{\max }$ \\
\hline $\mathrm{s}_{1}$ & $0.6 \mathrm{~mm}$ & $1.5 \mathrm{~mm}$ \\
\hline $\mathrm{s}_{2}$ & $0.6 \mathrm{~mm}$ & $3.5 \mathrm{~mm}$ \\
\hline $\mathrm{s}_{3}$ & $1.0 \mathrm{~mm}$ & $10 \mathrm{~mm}$ \\
\hline$\alpha$ & 0.4 & 0.3 \\
\hline
\end{tabular}

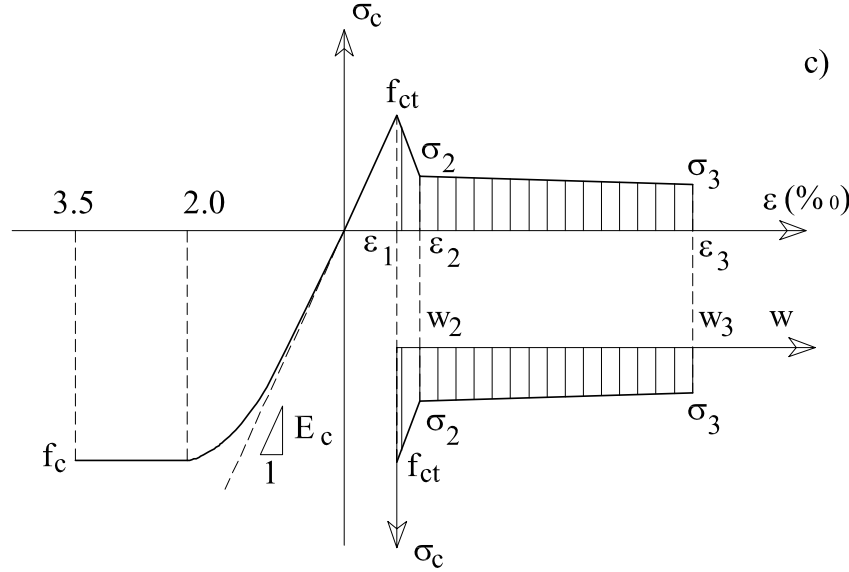

$$
\begin{aligned}
& \varepsilon_{1}=\mathrm{f}_{\mathrm{ct}} / \mathrm{E}_{\mathrm{c}} \\
& \varepsilon_{2}=\varepsilon_{1}+0.1 \% 0 \\
& \varepsilon_{3}=25.0 \% 0
\end{aligned}
$$

$\mathrm{f}_{\mathrm{ct}}=0.7 \mathrm{f}_{\mathrm{ctm}, \mathrm{fl}}(1.6-\mathrm{H})$

$\sigma_{2}=0.45 \mathrm{f}_{\mathrm{R}, 1} \mathrm{k}_{\mathrm{h}}$

$\sigma_{3}=0.37 \mathrm{f}_{\mathrm{R}, 4} \mathrm{k}_{\mathrm{h}}$

$\mathrm{k}_{\mathrm{h}}=$ size factor

Fig. (4). Constitutive relationships adopted in the model: a) fictitious crack model for ordinary concrete [6]; b) bond-slip relationship between steel and concrete [6, 14]; stress-strain relationship proposed by Rilem TC 162- TDF [8] for steel fiber reinforced concrete.

1 Assume a value for the normal force $N$.

2 Assume a value for the crack width $w$ at level of reinforcement in the cracked cross-section (type 1) (Fig. 3a).

3 Assume a trial value for the crack depth $h_{\mathrm{w}}$ in the cracked cross-section (Fig. 3a).

4 From the equilibrium of type 1 cross-section [Eqs.(4a-b)] it is possible to obtain the applied bending moment $M$.

5 From the equilibrium of type 2 cross-section [Eqs.(4a-b)] it is possible to obtain the states of stress and strain in the cross-section at incipient cracking (in particular, it is possible to obtain the concrete strain at level of reinforcement $\left.\varepsilon_{\mathrm{c}, \text { crit }}\right)$.

6 Assume a trial value for the length $l_{\text {tr }}$ of the considered block, which is divided into $n$ parts of length $\Delta z$.

7 Since the static and kinematical conditions are known at the borders of the considered block, it is possible to integrate numerically Eqs.(5-6) at the level of reinforcement. In a generic $i$-th point of the domain, the increments of concrete strains (Fig. 3b) are assumed to be similar to the decrements of steel strain (Fig. 3c), according to the following formulae:

$\varepsilon_{s, i}=\varepsilon_{s, 0}-\chi_{i}\left(\varepsilon_{s, 0}-\varepsilon_{s, n}\right)$

$\varepsilon_{c, i}=\varepsilon_{c, 0}-\chi_{i}\left(\varepsilon_{c, 0}-\varepsilon_{c, n}\right)$

where, $\varepsilon_{\mathrm{c}, \mathrm{n}}$ and $\varepsilon_{\mathrm{s}, \mathrm{n}}=$ strains in concrete and steel, respectively, in type 2 cross-section; $\varepsilon_{\mathrm{c}, 0}$ and $\varepsilon_{\mathrm{s}, 0}=$ strains in concrete and steel, respectively, in type 1 crosssection; and $\varepsilon_{\mathrm{i}}=$ coefficient of similarity $\left(0 \leq \chi_{\mathrm{i}} \leq 1\right)$.
By applying the explicit finite difference method to Eq.(6), and by substituting Eqs.(8a-b), it is possible to define $s_{\mathrm{i}}$ as a function of $\chi_{\mathrm{i}}$ :

$$
s_{i}=s_{i-1}-\Delta z\left\lfloor-\chi_{i}\left(\varepsilon_{s, 0}-\varepsilon_{s, n}-\varepsilon_{c, 0}+\varepsilon_{c, n}\right)+\varepsilon_{s, 0}-\varepsilon_{c, 0}\right\rfloor
$$

where, $\Delta z=l_{\text {tr }} / n=$ length of the $i$-th part of the domain. Similarly, if the explicit finite difference method is applied to Eq.(5), it is possible to compute $\varepsilon_{\mathrm{s}, \mathrm{i}}$ according to the following equation:

$\varepsilon_{s, i}=\varepsilon_{s, i-1}-\Delta z \frac{4}{E_{s} \Phi} \tau_{i-1}$

In other words, the solution of the system of Eqs.(4-6) within the domain $l_{\text {tr }}$ (which is a classical tensionstiffening problem for RC and R/FRC beams in bending) can be numerically obtained by moving from the point 0 to the point $n$ and computing $\varepsilon_{\mathrm{s}, \mathrm{i}}$ with Eq.(10), $\chi_{\mathrm{i}}$ with Eq.(8a), $\varepsilon_{\mathrm{c}, \mathrm{i}}$ with Eq.(8b) and $s_{\mathrm{i}}$ with Eq.(9).

8 If at the $n$-th point $s_{\mathrm{n}} \neq 0$, change $l_{\text {tr }}$ and go back to step 7 .

9 If at the $n$-th point $\varepsilon_{\mathrm{c}, \mathrm{n}} \neq \varepsilon_{\mathrm{c}, \text { crit }}$ (and therefore $\chi_{\mathrm{I}} \neq 1$ ), change $h_{\mathrm{w}}$ and go back to step 4 .

For a given pair of values $N$ and $w$, the previous procedure gives the values of the bending moment $M$ and of the crack depth $h_{\mathrm{w}}$ in the cracked cross-section, the maximum crack width $w_{\max }$, and the maximum distance between cracks $s_{\mathrm{r}, \max }=2 l_{\mathrm{tr}}$ (the minimum distance between cracks is $\left.l_{\text {tr }}\right)$. Such approach, in contrast with the semiempirical requirements of the codes [4, 6-8], permits to compute all the main characteristics of the crack pattern. Moreover, with the increase of $w$ and $M$, the experimentally detected reduction of $l_{\mathrm{tr}}$ is correctly predicted. On the 
contrary, building codes [6-8] impose a fixed value for the average distance between the cracks, which generally refers to the stabilized crack pattern at the end of the serviceability stage.

\section{COMPARISON WITH EXPERI-MENTAL DATA}

To validate the proposed approach, the results obtained with the previous procedure are compared with those measured in a series of experimental tests [9, 15-16]. More precisely, the crack patterns of the eight $\mathrm{RC}$ and $\mathrm{R} / \mathrm{FRC}$ beams reported in Table $\mathbf{1}$ are taken into consideration. In the same Table, the mechanical properties of the cement-based composites, which have to be introduced in the constitutive relationship of Fig. (4), are also defined. In all cases, cracks are referred to the constant moment zone of beams in four point bending.

The geometrical properties of the beams tested by (Vandewalle) [9], made of RC (beams B1) and R/FRC (beams B2, B3, B4 and B5), are reported in Table 1 and Fig. (5a). In the constant moment zone, without any shear reinforcement, crack width has been measured at different value of the applied bending moment $M$.

The maximum crack width in the beams B1 and B3, reported in Fig. (5b) and Fig. (5c) respectively, has been estimated to be 1.7 times the average values measured by (Vandewalle) [9]. In the same Figures, the measured values are compared with those computed by code rules $[4,7,8]$ and by means of the block model previously described. The proposed approach seems to predict effectively the maximum crack width measured in the beams B1 and B3, and shows the effective capability of the fibers to reduce crack width.
The proposed model also explains the possible variation of crack distance in the beam B1 (Fig. 5d) and the beam B3 (Fig. 5e). The average values of the measured crack spacing, of those computed with (Eurocode 2) [7] for the beam B1 [the value obtained with Eq.(2) has been reduced by the factor 1.7] and of those computed with Rilem TC 162-TDF [8] for beam_2 [Eq.(3)], fall within these ranges. Since code rules refer to cross-sectional models, they can only provide one value of crack distance.

Conversely, with the proposed block model, and according to the experimental evidence, a reduction of $s_{\mathrm{rm}}$ with the applied bending moment is observed.

A good agreement between numerical results and experimental data is also obtained for beams B6 and B7 tested by (Tan et al.) [15], whose geometrical properties are reported in Fig. (6a). In these two cases, the proposed model confirms the capability of predicting the maximum crack width of RC (Fig. 6b) and R/FRC (Fig. 6c) beams.

Finally, the beam B8 reported in Table 1, made of reinforced concrete without fibers, is here taken into consideration. In the constant moment zone of the beam, cracks appeared according to the order reported in Fig. (7a). By means of the Moire method with superimposed grids, (Giuriani and Sforza) [16] were able to measure the depth $h_{\mathrm{w}}$ of the cracks n. 6, 7 and 8 . The experimental results, reported in Fig. (7b) in terms of applied moment $M$ in the constant moment zone vs. relative crack depth $h_{\mathrm{w}} / H$, are satisfactorily predicted by the proposed model, which provides all the characteristics $\left(s_{\mathrm{r}}, w_{\max }\right.$ and $\left.h_{\mathrm{w}}\right)$ of crack patterns. According to (Beeby) [17], this aspect is of crucial importance, because new approaches for the evaluation of crack width should be able to evaluate the shape, and therefore the depth, of cracks across the steel reinforcement.

Table 1. Geometrical and Mechanical Properties of the Beams

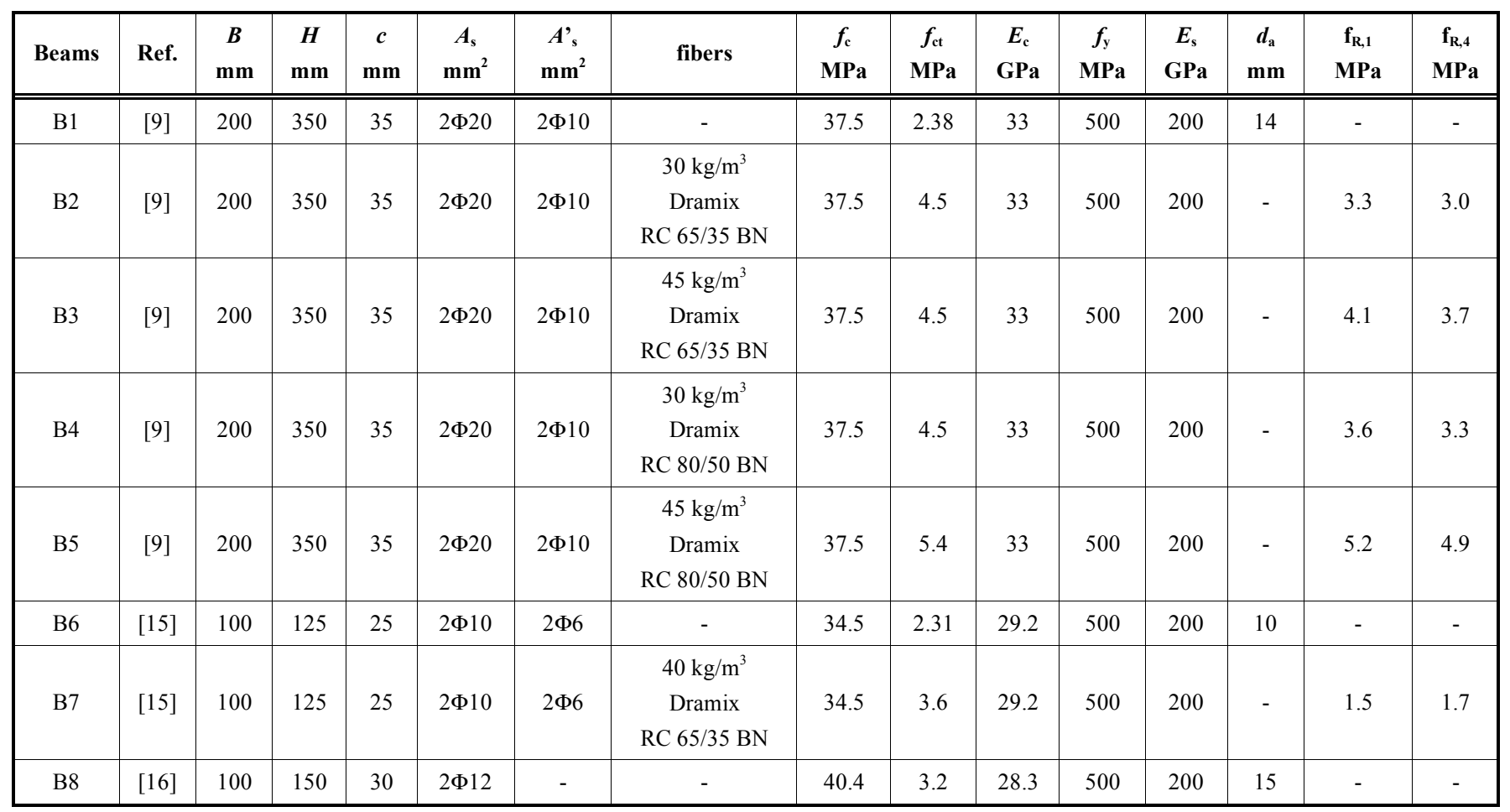




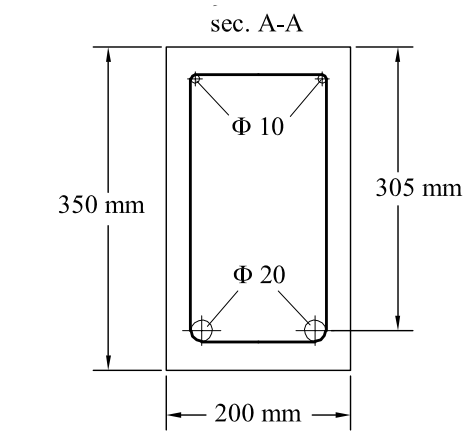

a)
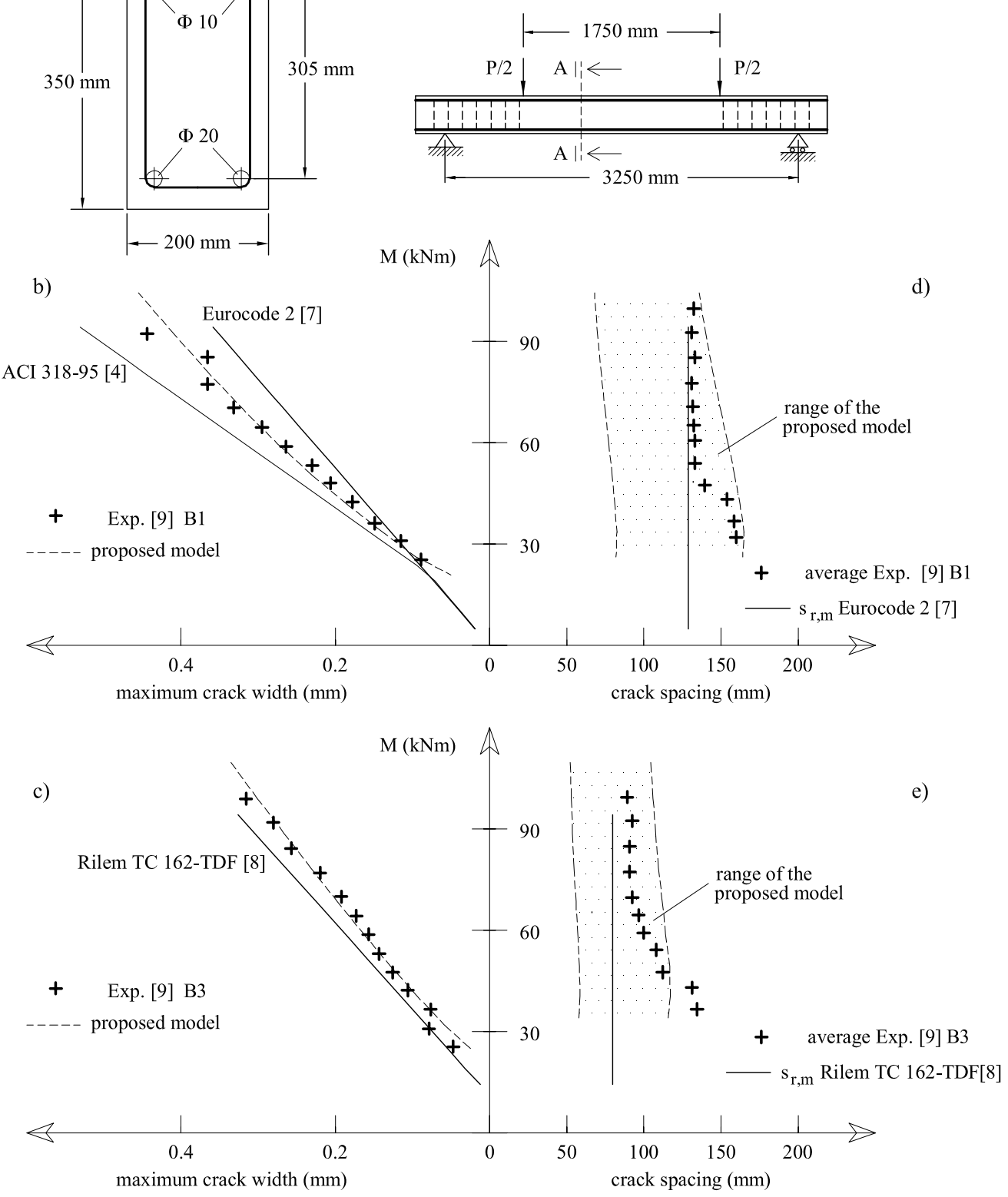

Fig. (5). The beams tested by Vandewalle [9]: a) geometrical properties of the beams B1 and B3; b) maximum crack width vs. bending moment in the constant moment zone of the beam B1; c) maximum crack width vs. bending moment in the constant moment zone of the beam B3; d) crack spacing vs. bending moment in the constant moment zone of the beam B1; e) crack spacing vs. bending moment in the constant moment zone of the beam B3.

\section{THE EFFECT OF REINFORCING INDEX RI}

All the test data measured by (Vandewalle) [9] are now compared with the numerical results computed with the proposed model. Instead of analyzing the crack growth, the crack patterns of the beams B1, B2, B3, B4 and B5, observed at same level of bending moment $(M=69 \mathrm{kN} \mathrm{m})$ in the constant moment zone (Fig. 5a), are taken into consideration.

In Fig. (8a) are reported the diagrams of normalized maximum crack width $w_{\max } / w_{\max , \mathrm{B} 1}$ (i.e., the ratio between the maximum crack width of a fiber reinforced beam, measured at $M=69 \mathrm{kN} \mathrm{m}$, and the cor-responding value measured in the beam B1) vs. Reinforcing Index RI (i.e., the product of fiber volume $V_{\mathrm{f}}$, expressed in percent, by the fiber aspect ratio $L / D$ ). Similarly, the diagrams of computed and measured normalized maximum crack length $s_{\mathrm{r}, \max } / s_{\mathrm{r}, \max , \mathrm{B} 1}$ (i.e., the ratio between the maximum crack length of a fiber reinforced beam, measured at $M=69 \mathrm{kN} \mathrm{m}$, and the corresponding value measured in the beam B1) vs. the Reinforcing Index $R I$ are reported in Fig. (8b).

The assumption of $R I$ as a term of comparison permits not only to compare the effects of different types and volumes of fibers added to concrete, but also to draw a parallel with the mechanical behaviour of FRC in compression. Uniaxial compressive tests on cylindrical specimens have shown an increase of the Fracture Toughness with the increase of RI (Fanella and Naaman) 

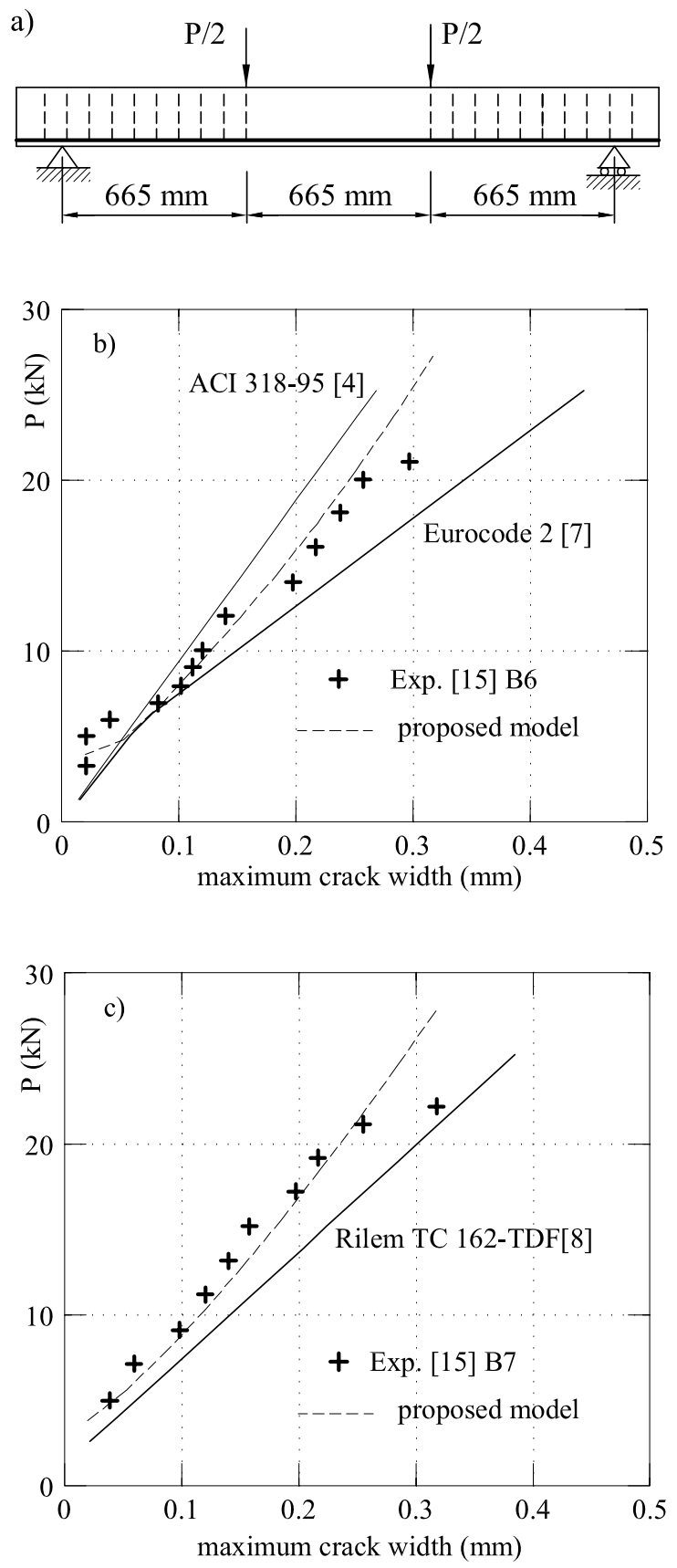

Fig. (6). The beams tested by Tan et al. [15]: a) geometrical properties of the beams $\mathrm{B} 6$ and $\mathrm{B} 7$; b) maximum crack width vs. applied load of the beam B6; c) maximum crack width vs. applied load of the beam B7.

[18]. In the same way, the higher the reinforcing index, the higher the ductility of R/FRC beams which fail by crushing of concrete in the compression [19].

If $R I$ increases in the tensile zones of cement-based beams, their crack pattern tends to be less heavy (with narrower cracks located at small distances). This is shown in Fig. (8a), where a reduction of $w_{\max } / w_{\max , \mathrm{B} 1}$ and, consequently, a consistent structural advantage due to the presence of fibers, can be observed both numerically and experimentally. To be more precise, if $R I=45 \%\left(45 \mathrm{~kg} / \mathrm{m}^{3}\right.$ a)
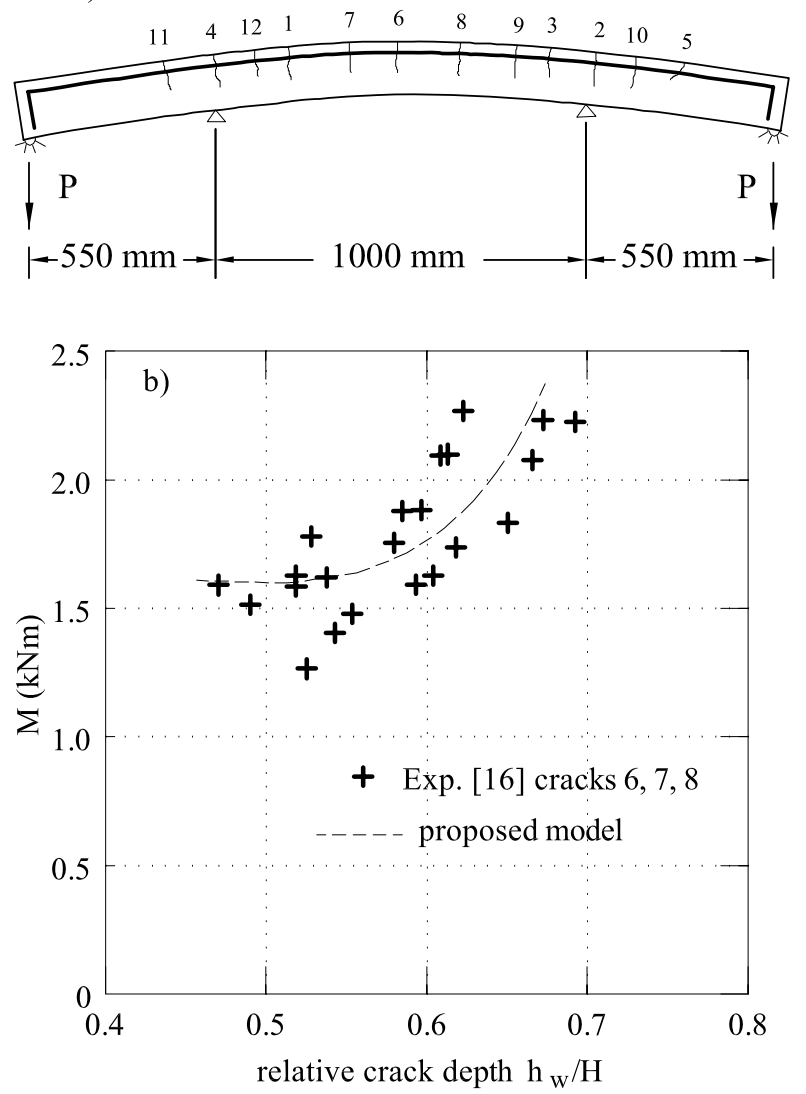

Fig. (7). The beam tested by Giuriani and Sforza [16]: a) geometrical properties of the beam $\mathrm{B} 8$; b) relative crack depth vs. bending moment in the constant moment zone of the beam B8.

of Dramix 80/-50 BN), the corresponding R/FRC beam shows maximum crack widths $40 \%$ lower than those measured in a similar RC beam. This is also true for crack distances (Fig. 8b), which are significantly reduced as $R I$ increases.

It is important to remark the practical utility of the diagrams $w_{\max } / w_{\max , \mathrm{B} 1}$ vs. $R I$ (Fig. 8a). In fact, when environmental conditions require reduction of the crack width (with respect to that of a RC beam made of ordinary concrete), it is possible to define the corresponding value of $R I$ and, therefore, the volume content and/or the aspect ratio of fibers.

\section{SIZE EFFECTS OF CRACK PATTERNS}

In the last decades, the so-called size effect has been largely analyzed in structures made of quasi-brittle materials like concrete (see the final report of Rilem TC QFS [20] for a review). Conversely, the effects of the structural dimension of $\mathrm{RC}$ and $\mathrm{R} / \mathrm{FRC}$ beams on the main aspects of crack patterns have not been investigated, neither theoretically nor experimentally. For these reasons, the proposed model is here adopted to define the values of crack width and crack distances, in terms of $w_{\max } / w_{\max , \mathrm{B} 1}$ and $s_{\mathrm{r}, \max } / s_{\mathrm{r}, \max , \mathrm{B} 1}$, produced by different reinforcing indexes and geometrical dimensions of the structure. The beams taken into consideration are depicted in Fig. (9a). Their geometrical dimensions are obtained by scaling the (Vandewalle's beam) 

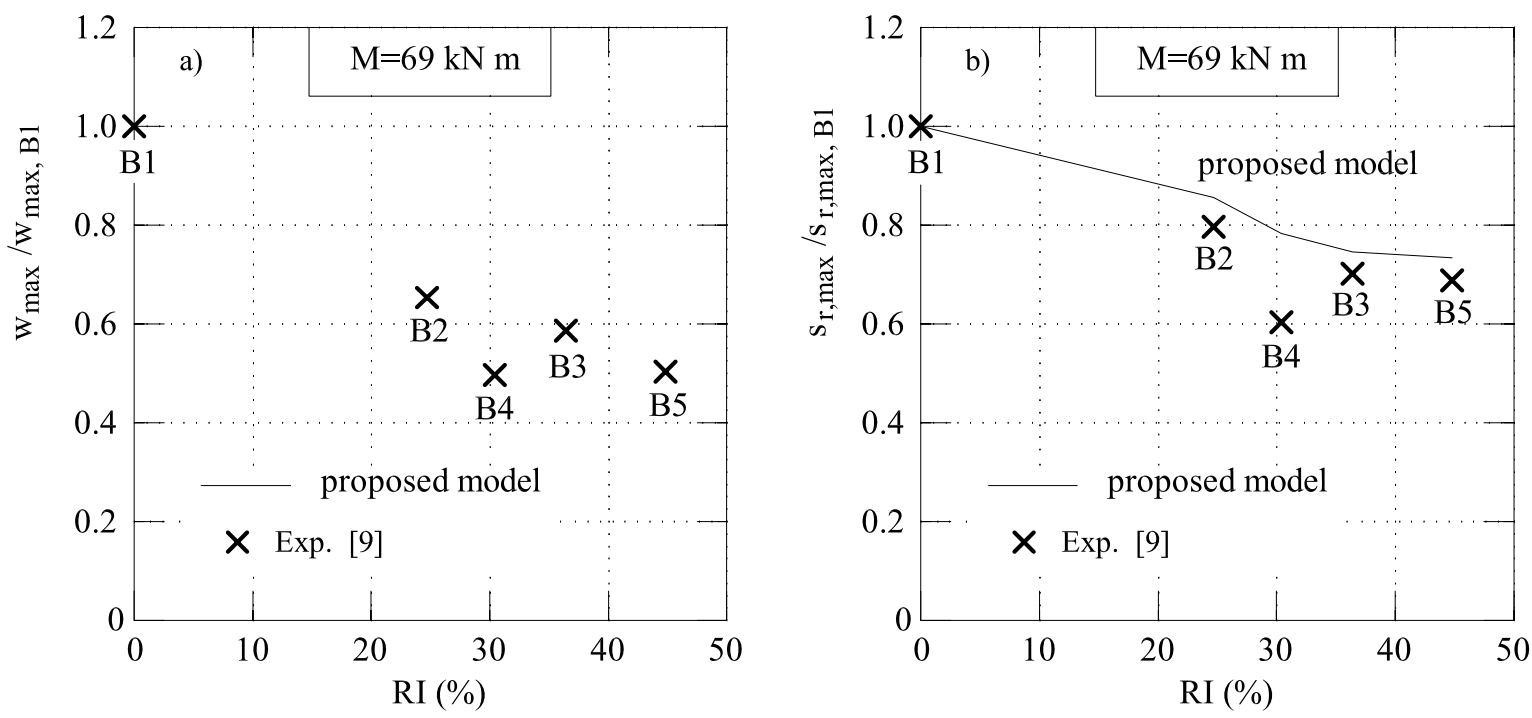

Fig. (8). The crack patterns of Vandewalle's beams [9] at $M=69 \mathrm{kN} \mathrm{m}$ : a) normalised crack width vs. reinforcing index; b) normalised crack distance vs. reinforcing index.

[9] of a size factor $S F$. In the present work only the cases of $S F=1$ (which is exactly the beam tested by (Vandevalle) [9] and $S F=0.5$ are investigated.

When $S F=1$, the beam of Fig. (9a) yields the ultimate bending moment, computed with the classical formula of bearing capacity [21], equal to $M_{\mathrm{u}}=0.9(H-c) \cdot f_{\mathrm{yk}} \cdot A_{\mathrm{s}} \cong 86$ $\mathrm{kN} \mathrm{m}$, whereas if $S F=0.5$, the value of $M_{\mathrm{u}}=0.9(H-c)$.

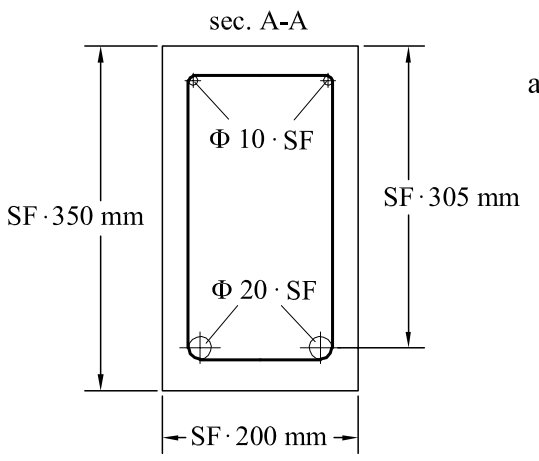

a)
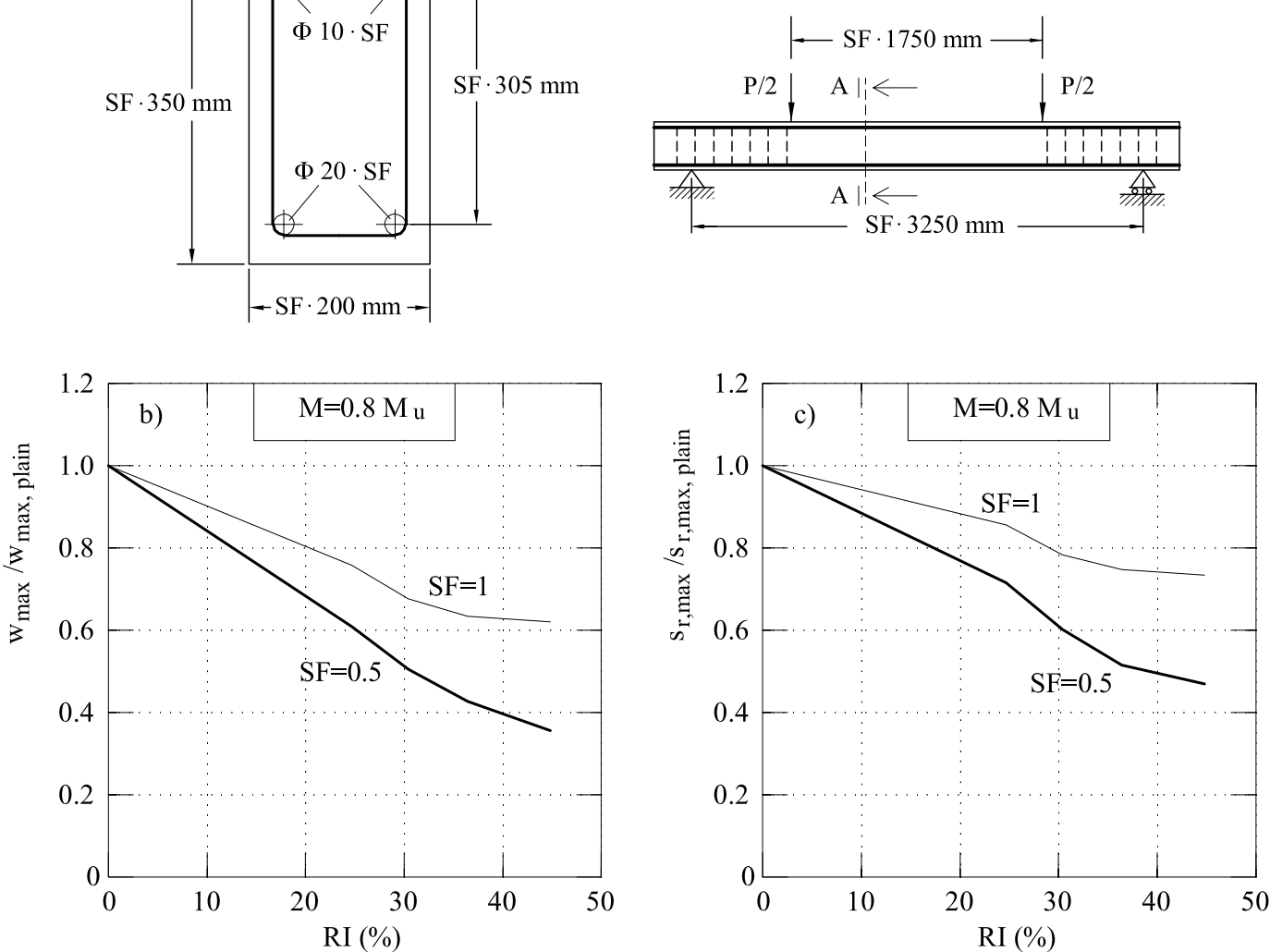

Fig. (9). Maximum crack width and crack distance at different scales: a) the geometrical properties of four point bending beams; b) normalised crack width vs. reinforcing index at $\left.M=0.8 M_{\mathrm{u}} ; \mathbf{b}\right)$ normalized crack distance vs. reinforcing index at $M=0.8 M_{\mathrm{u}}$. $f_{\mathrm{yk}} \cdot A_{\mathrm{s}} \cong 11 \mathrm{kN} \mathrm{m}$ is obtained. It must be remarked that all the beams of Fig. (9a) have the same geometrical percentage of reinforcement bars, independently of the size factor $S F$.

The normalized values of maximum crack width and crack distance, evaluated with the proposed model, are reported in Fig. (9b) and Fig. (9c), respectively, as functions of the reinforcing index $R I$ and size factor $S F$. In both cases, 
$w_{\max }$ and $s_{\mathrm{r}, \max }$ are related to the constant moment zone of a four point bending beam, subjected to a bending moment $M=80 \% M_{\mathrm{u}} \quad$ (that is, $M \cong 69 \mathrm{kN} \mathrm{m}$ if $S F=1$, and $M \cong 9 \mathrm{kN} \mathrm{m}$ if $S F=0.5)$. These values are normalized respect to $w_{\text {max,plain }}$ and $s_{\mathrm{r} \text {,max,plain }}$ measured in the same beams without any fiber reinforcement. As Fig. (9b) shows, for a given value of $R I$, the ratio $w_{\max } / w_{\text {max,plain }}$ decreases as the size factor $S F$ reduces. In the same way, the normalized crack distance $s_{\text {r,max }} / s_{\text {r,max,plain }}$ shows a similar trend (Fig. 9c).

The conclusion is that, the higher the geometrical dimensions of the structure (e.g., the massive concrete tunnel linings), the lower the effect produced by fibers. This is in accordance with the classical statements of Fracture Mechanics of quasi-brittle material, which become perfectly brittle at large scale [20]. In other words, the control of crack width should be particularly required for massive structures, even in presence of fibers. For this reason, the model here proposed for the analysis of crack patterns has been applied, in conjunction with the model already introduced for the evaluation of the minimum reinforcement area of steel reinforcing bars [1], for designing the first cast-in-situ $\mathrm{R} / \mathrm{FRC}$ tunnel linings in Italy [22].

\section{CONCLUSIONS}

A new model, able to define crack width, crack spacing and crack depth in RC and R/FRC structures, has been proposed. From the comparison with the experimental data, the following conclusions can be drawn:

- The proposed block model gives a more detailed evaluation of crack pattern. In particular, it provides the evolution of crack width, crack depth and crack distance with the increase of external actions, both in $\mathrm{RC}$ and $\mathrm{R} / \mathrm{FRC}$ members subjected to bending and normal actions.

- The semi-empirical or empirical cross-sectional approaches, suggested by the code rules, do generally overestimate crack width, and thus underestimate the effect produced by fibers.

- The proposed model seems to confirm qualitatively the beneficial actions of the fibers in reducing the maximum crack width and crack distance, and thus in reducing the vulnerability of concrete structures to corrosion of steel rebars.

- In R/FRC beams in bending, the width and the distance of cracks decrease with the increase of reinforcing index $R I$. By changing this parameter, it is possible to tailor a structural element capable to satisfy the serviceability conditions required by code rules.

Despite the presence of fibers, massive structures, such as concrete tunnel linings, are particularly vulnerable to cracking phenomenon. Thus, it is desirable that new tests will be performed in order to investigate the size effect of cracking in RC and R/FRC beams.

\section{ACKNOWLEDGEMNTS}

The authors wish to express their gratitude to the Italian Ministry of University and Research for financing this research work (PRIN 2006), and to Bekaert for the continuous support of the research.

\section{LIST OF SYMBOLS}

$\begin{array}{lll}A_{\mathrm{c}} & = & \text { Concrete area in a RC or R/FRC cross-section } \\ A_{\mathrm{c}, \mathrm{eff}} & = & \text { Effective concrete area in tension } \\ A_{\mathrm{s}} & = & \text { Area of steel reinforcing bars in tension } \\ A_{\mathrm{s}}^{\prime} & = & \text { Area of steel reinforcing bars in compression } \\ \boldsymbol{B} & = & \text { Width of the beam cross-section } \\ c & = & \text { Concrete cover } \\ d_{\mathrm{a}} & = & \text { Maximum aggregate size } \\ E_{\mathrm{c}} & = & \text { Young's modulus of concrete } \\ E_{\mathrm{s}} & = & \text { Young's modulus of steel } \\ f_{\mathrm{c}} & = & \text { Cylindrical compressive strength of concrete } \\ & & \text { or FRC } \\ f_{\mathrm{ck}} & = & \text { Characteristic value of } f_{\mathrm{c}} \\ f_{\mathrm{ct}} & = & \text { Tensile strength of concrete or FRC } \\ f_{\mathrm{ctm}, \mathrm{fl}}= & \text { Average flexural tensile strength of concrete or }\end{array}$

$f_{\mathrm{R}, 1}, \quad=\quad$ Residual strengths obtained from a three point $f_{\mathrm{R}, 4} \quad$ bending test on notched FRC beams [8].

$f_{\mathrm{y}}=$ Yield Strength of the longitudinal steel reinforcing bars

$f_{\mathrm{yk}}=$ Characteristic value of $f_{\mathrm{y}}$

$H=$ Height of the beam cross-section

$h_{\mathrm{w}}=$ Depth of a primary crack

$k_{1}, k_{2},=\quad$ Non dimensional coefficients in Eqs.(2-3)

$k_{3}, k_{4}, k_{5}$

$L / D=$

Fiber aspect ratio $(L=$ length of the fiber; $D$ diameter of the fiber)

$l_{\mathrm{tr}}=\quad$ Length of the block between type 1 and type 2 cross-sections

$M=$ Bending moment applied to a beam crosssection

$M_{\mathrm{u}}=\quad$ Ultimate bending moment

$N=$ Normal force applied to a beam cross-section

$n=\quad$ Number of segments contained within $l_{\mathrm{tr}}$

$P \quad=\quad$ Loads applied to a beam in four point bending

$p_{\mathrm{s}}=$ Perimeter of steel reinforcing bars in tension

$R I=$ Reinforcing index $(\%)=V_{\mathrm{f}}-L / D$

$s \quad=\quad$ Slip between steel and concrete

$s_{1}=\quad$ Slip between steel and concrete at $\tau_{\max }$

$S F=$ Size factor

$s_{\mathrm{r}} \quad=\quad$ Crack distance

$s_{\mathrm{r}, \mathrm{m}}=\quad$ Average value of crack distance

$s_{\mathrm{r}, \max }=\quad$ Maximum value of crack distance

$V_{\mathrm{f}}=$ Volumetric percentage of fibers

$w=$ Crack width at level of reinforcement

$w_{\mathrm{k}}=$ Characteristic value of $w$ 


$$
\begin{aligned}
& w_{\max }=\quad \text { Maximum value of } w \\
& y=\text { Vertical coordinate } \\
& z=\text { Horizontal coordinate } \\
& \alpha=\text { Exponent in Eq.(7) } \\
& \beta=\text { Coefficient relating the average crack spacing } \\
& \text { to the design value } \\
& \chi_{\mathrm{i}}=\text { Coefficient of similarity of Eqs.(8a-b) } \\
& \Delta z=l_{\text {tr }} / n=\text { Length of the } \mathrm{i} \text {-th part of the domain } l_{\mathrm{tr}} \\
& \varepsilon_{\mathrm{c}}(y)=\quad \text { Strains in concrete or FRC } \\
& \varepsilon_{\mathrm{cm}}=\text { Mean strain in concrete or FRC at level of } \\
& \text { reinforcement between cracks } \\
& \varepsilon_{\mathrm{c}, \text { crit }}=\text { Strain in concrete or FRC at level of } \\
& \text { reinforcement in the type } 2 \text { cross-section (Fig. } \\
& \text { 2b) } \\
& \varepsilon_{\mathrm{s}}=\quad \text { Strain in steel reinforcing bars in tension } \\
& \varepsilon_{\mathrm{sm}}=\text { Mean strain in steel reinforcing bars between } \\
& \text { cracks } \\
& \varepsilon_{\mathrm{s}}^{\prime}=\text { Strain in steel reinforcing bars in compression } \\
& \phi=\text { Bar diameter } \\
& \rho=A_{\mathrm{s}} / A_{\mathrm{c}, \text { eff }}=\text { Effective reinforcement ratio } \\
& \sigma_{\mathrm{c}}(y)=\quad \text { Stress in concrete or FRC } \\
& \sigma_{\mathrm{s}}=\text { Stress in steel reinforcing bars in tension } \\
& \sigma_{\mathrm{s}}^{\prime}=\text { Stress in steel reinforcing bars in compression } \\
& \tau=\text { Bond stress between steel and concrete } \\
& \tau_{\mathrm{f}}=\text { Residual bond stress between steel and } \\
& \text { concrete } \\
& \tau_{\max }=\text { Maximum bond stress between steel and } \\
& \text { concrete }
\end{aligned}
$$

\section{REFERENCES}

[1] B. Chiaia, A. P. Fantilli and P. Vallini, "Evaluation of minimum reinforcement ratio in FRC members and application to tunnel linings", Materials and Structures. vol. 40, 6, pp. 593-604, 2007.

[2] J. C. Walraven, "Fracture mechanics of concrete and its role in explaining structural behaviour", in Fracture Mechanics of Concrete and Concrete Structures (FRAMCOS 6), 2007, pp. 12651275 .

[3] A. Borosnyoi, and G. L. Balazs, "Models for flexural cracking in concrete: the state of art", Structural Concrete, vol. 6, 2, pp. 53-62, 2005.
[4] American Concrete Institute, ACI 318-95: Building Code Requirements for Structural Concrete, Farmington Hills: Michigan, 1995.

[5] P. Gergely and L. A. Lutz, "Maximum Crack Width in Reinforced Concrete Flexural Members", Causes, mechanism and control of cracking in concrete, SP-20, American Concrete Institute, 1968, pp. 87-177.

[6] Comitè Euro-International du Bèton, "CEB-FIP Model Code 1990", CEB Bulletin d'Information, 213/214, 1993.

[7] BSEN 1992-1-1. Eurocode 2: Design of concrete structures, General rules and rules for buildings, (Part 1) 2004.

[8] Rilem TC 162 - TDF, " $\sigma-\varepsilon$ design method - final recommendation”, Materials and Structures, vol. 36, pp. 560-567, 2003.

[9] L. Vandewalle, "Cracking behaviour of concrete beams reinforced with a combination of ordinary reinforcement and steel fibers", Materials and Structures, vol. 33, pp. 164-170, 2000.

[10] A. P. Fantilli and P. Vallini, "Tension stiffening range in FRC elements", in 6th RILEM Symposium on Fibre Reinforced Concretes (BEFIB 2004), pp. 847-856, 2004.

[11] F. Levi, "On Minimum Reinforcement in Concrete Structures", ASCE Journal of Structural Engineering, vol. 111,12, pp. 27912796, 1985.

[12] A. P. Fantilli, D. Ferretti, I. Iori and P. Vallini, "Flexural Deformability of Reinforced Concrete Beams", ASCE Journal of Structural Engineering, vol. 124, 9, pp. 1041-1049, 1998,

[13] A. P. Clark, "Cracking in reinforced concrete flexural members", Journal of the American Concrete Institute, vol. 27, 8, pp. 851-862, 1956.

[14] M. Harajli, B. Hamad, and K. Karam, "Bond-slip response of reinforcing bars embedded in plain and fiber concrete", $A S C E$ Journal of Materials in Civil Engineering, vol. 14, 6, pp. 503-511, 2002.

[15] K.-H. Tan, P. Paramasivam and K.-C. Tan, "Cracking characteristics of reinforced steel fiber concrete beams under shortand long- term loadings", Advanced Cement Based Materials, vol. 2, pp. 127-137, 1995.

[16] E. Giuriani and C. Sforza, "Relationships between local and average moment-curvature for a R.C. beam under increasing and repeated imposed curvatures- experimental research by means of the Moiré method with superimposed grids", Studies and Researches, vol. 3, pp.177-204, (in Italian) 1981.

[17] A. W. Beeby, "The influence of the parameter $\phi /$ peff on the crack widths", Structural Concrete, vol. 5, 2, pp. 71-83, 2004.

[18] D. A. Fanella and A. E Naaman, "Stress-strain properties of fiber reinforced mortar in compression", ACI Journal, vol. 82, 4, pp. 475-483, 1985

[19] A. P. Fantilli, H. Mihashi and P. Vallini, "Post-peak behaviour of cement-based materials in compression", ACI Materials Journal, vol. 104, 5, pp. 501-510, 2007.

[20] Rilem TC QFS, "Quasibrittle fracture scaling and size effect - Final report", Materials and Structures, vol. 37, pp. 547-568, 2004.

[21] M. P.Collins and D. Mitchell, Prestressed Concrete Structures, Englewood Cliffs: Prentice Hall, 1991.

[22] B. Chiaia, A. P. Fantilli and P. Vallini, "Minimum reinforcement and fiber contribution in tunnel linings: the Italian experience", in Proceedings of the Fourth International Structural Engineering and Construction Conference (ISEC 4), 2007, pp. 365-370. 